\title{
Trocas gasosas de plantas de Handroanthus impetiginosus (Mart. ex DC) Mattos submetidas ao déficit hídrico e posterior reidratação
}

Gas exchange of Handroanthus impetiginosus (Mart. ex DC) Mattos plants under water stress and rehydration

\author{
Jéssica Lima Pessoa, Antonio Lucineudo Oliveira Freire* e Amanda Silva Costa
}

\author{
Recebido em 18/07/2016 / Aceito em 14/03/2017
}

\section{RESUMO}

O conhecimento de aspectos relacionados à ecofisiologia das espécies vegetais presentes na Caatinga é escasso, sendo necessário estudos que possibilitem o entendimento das adaptações apresentadas pelas plantas para conseguir sobreviver em condições de baixa disponibilidade hídrica. Nesse sentido, desenvolveu-se este estudo com o objetivo de analisar as trocas gasosas de plantas jovens de ipêroxo submetidas ao déficit hídrico progressivo, através da suspensão da irrigação, e à reidratação. As plantas com 12 meses de idade, crescendo em sacos plásticos pretos contendo $5 \mathrm{~kg}$ de substrato, foram submetidas a dois tratamentos: irrigado (tratamento controle) e de déficit hídrico, imposto através da suspensão da irrigação. Diariamente foram avaliadas o conteúdo relativo de água (CRA), condutância estomática (gs), transpiração (E), concentração intercelular de $\mathrm{CO}_{2}(\mathrm{Ci})$ e fotossíntese (A) e calculada a eficiência instantânea no uso da água (EUA). Após permanecerem dez dias sob a condição de déficit, a irrigação foi restabelecida, e foi avaliada a recuperação das mesmas. O déficit hídrico reduziu de maneira rápida e progressiva todos os parâmetros avaliados, exceto o Ci. Após a retomada do fornecimento de água, as plantas apresentaram recuperação nesses processos fisiológicos. O déficit hídrico não afetou a eficiência instantânea no uso da água das plantas de ipê-roxo.

PALAVRAS-CHAVE: eficiência no uso da água, fotossíntese, transpiração

\footnotetext{
ABSTRACT

Knowledge of aspects related to the ecophysiology of plant species present in Caatinga is scarce, needing studies that allow the understanding

of the adaptations made by plants to be able to survive under conditions of low water availability. Accordingly, this study was developed with the purpose of analyzing the gas exchange of ipê-roxo seedlings subjected to progressive water stress, through the suspension of irrigation, and rehydration. 12 month old plants, growing up in black plastic bags containing $5 \mathrm{~kg}$ of substrate, were subjected to two treatments: irrigated and water stress imposed by withholding water. The relative water content, stomatal conductance, transpiration rate, intercellular $\mathrm{CO}_{2}$ concentration, and photosynthetic rates were evaluated daily. After ten days remaining under this stress condition, irrigation was restored, and recovery was evaluated. Drought stress decreased rapidly and also progressively the relative water content, stomatal conductance, transpiration, carboxylation efficiency and photosynthesis of plants. An increase in intercellular $\mathrm{CO}_{2}$ concentration with increase of water stress was observed. After the resumption of water supply, the plants showed recovery of these physiological processes. Water stress did not affect the water efficiency use of plants.

KEYWORDS: water efficiency use, photosynthesis, transpiration.

\section{INTRODUÇÃO}

Aágua é crucial para a existência, sobrevivência e perpetuação de qualquer forma de vida (PIMENTEL 2004), sendo uma condição determinante para a distribuição das espécies nos diversos ecossistemas (OTIENO et al. 2005). É o principal constituinte dos vegetais, representando $50 \%$ da massa fresca nas plantas lenhosas e cerca de 80 a 95\% nas herbáceas, e é necessária para a turgescência das células e tecidos e essencial para o transporte de solutos e crescimento 
(FIGUEIRÔA et al. 2004).

Asua deficiência causa alterações na morfologia, anatomia e fisiologia das plantas, afetando o seu crescimento (BEZERRA et al. 2003). A tolerância da planta a essa condição adversa constitui-se em importante mecanismo de adaptação, garantindo o crescimento e a produção de biomassa em condições de baixa disponibilidade de água. No entanto, as respostas das plantas ao déficit hídrico podem variar com a espécie vegetal, a idade das plantas e com o grau de déficit imposto. Nesse sentido, as respostas das plantas a essa redução na disponibilidade de água, bem como o grau de tolerância e as estratégias de adaptação a tal condição podem explicar as diferenças na sobrevivência e na distribuição das plantas (GEBREKIRSTOS et al. 2006).

O conhecimento de aspectos relacionados à ecofisiologia das espécies vegetais presentes na Caatinga é escasso, sendo necessários estudos que possibilitem o entendimento das adaptações apresentadas pelas plantas para conseguir sobreviver em condições de baixa disponibilidade hídrica sazonal, característica desse bioma. Nesse sentido, estudos têm sido conduzidos com o objetivo de verificar o comportamento de mudas espécies ocorrentes nesse bioma, em relação à redução na disponibilidade de água do substrato (CABRAL et al. 2004, SILVA et al. 2004a).

Esse trabalho teve como objetivo analisar as trocas gasosas de plantas jovens de ipê-roxo submetidas ao déficit hídrico progressivo, através da suspensão da irrigação, bem como o comportamento após o restabelecimento da irrigação.

\section{MATERIAL E MÉTODOS}

O experimento foi conduzido em ambiente protegido, com cobertura plástica e telado nas laterais, no Viveiro Florestal da Unidade Acadêmica de Engenharia Florestal, Centro de Saúde e Tecnologia Rural, Universidade Federal de Campina Grande (UAEF/CSTR/UFCG), Campus de Patos, PB ( $7^{\circ} 03^{\prime} 34^{\prime \prime} \mathrm{S}$ e $37^{\circ} 16^{\prime} 30^{\prime \prime} \mathrm{O}$ ), entre junho de 2012 e agosto de 2013.

As sementes foram coletadas em árvores mantidas na UFCG, Campus de Patos e, após uniformização, foram submetidas à retirada das alas e semeadas em sacos plásticos pretos contendo $5 \mathrm{~kg}$ de substrato, composto de terra de subsolo e esterco bovino, na proporção 2:1 (v/v). As mudas foram mantidas em ambiente telado (50\% de luminosidade) e irrigadas manualmente com auxílio de regador. A superfície superior do substrato foi coberta com um plástico opaco, no intuito de evitar a perda de água por evaporação. O controle do teor de umidade do substrato foi feito diariamente.

Ao atingirem 12 meses de idade, as plantas foram submetidas a dois regimes hídricos, correspondendo ao tratamento irrigado (controle) e ao tratamento de déficit hídrico. No primeiro, as plantas foram irrigadas conforme descrito anteriormente, enquanto que no tratamento de déficit hídrico ocorreu a suspensão da irrigação, o qual persistiu até que a taxa de fotossíntese das plantas atingissem valores próximos ou iguais a zero, o que ocorreu dez dias após a suspensão da irrigação. Em seguida houve a retomada do fornecimento de água às plantas, e foi avaliada a recuperação das mesmas, que prosseguiu até que a taxa de fotossíntese das plantas dos tratamentos fossem semelhantes.

Durante o período da imposição dos tratamentos, e a recuperação, foram avaliadas taxa de transpiração (E), condutância estomática (gs), taxa de fotossíntese (A) e concentração intercelular de $\mathrm{CO}_{2}(\mathrm{Ci})$, com o auxílio do analisador portátil de fotossíntese LCpro$\mathrm{SD}$ (ADC BioScientific Ltd.). Essas avaliações foram feitas entre 9:00 e 10:00 horas da manhã, em folíolos completamente expandidos inseridos no segundo nó a partir do ápice das plantas. De posse dos valores de A e E, foi calculada a eficiência no uso da água (EUA). Dividindo-se os valores de A e Ci, obteve-se a eficiência de carboxilação $(\mathrm{A} / \mathrm{Ci})$. Após a realização das leituras acima, folhas foram coletadas para determinação do conteúdo relativo de água (TRA), através de discos foliares, segundo metodologia descrita por WHEATHERLEY (1950).

Os tratamentos foram distribuídos em delineamento experimental inteiramente casualizado, com 4 repetições e 3 plantas por repetição. Os dados foram submetidos à análise de variância e as médias comparadas entre si, pelo teste de Tukey.

\section{RESULTADOS E DISCUSSÃO}

As plantas submetidas ao déficit hídrico apresentaram redução no conteúdo relativo de água (TRA) ao longo do período em que essa condição foi imposta (Figura 1B), como era de se esperar, uma vez que ocorria redução na disponibilidade de água para as plantas e, consequentemente, na absorção por parte 
das mesmas.

As diferenças significativas entre os tratamentos foram observadas logo no segundo dia após a suspensão da irrigação. Nesse dia, as plantas do tratamento de déficit hídrico apresentaram redução de $15 \%$ no TRA das folhas, em relação às plantas irrigadas. As diferenças entre esses tratamentos aumentaram progressivamente e, aos 10 dias da suspensão da irrigação, os valores de TRA foram, respectivamente, $83 \%$ e $26 \%$ nas plantas irrigadas e sob déficit hídrico, correspondendo a uma redução de $57 \%$. Constata-se, então, que o grau de déficit foi severo, levando as plantas a níveis muito baixos de água nos seus tecidos, porém não letal, pois ocorreu recuperação após a retomada da irrigação das plantas, mesmo que de forma lenta.

De acordo com PARDO (2010), o valor de TRA em tecidos bem hidratados pode variar entre 85 e $95 \%$, sendo que $50 \%$ é considerado crítico e letal para as plantas, porém algumas espécies xerófilas podem atingir esse valor sem que ocorra a morte dos tecidos, o que pode ser o caso das plantas de ipêroxo nesse estudo, durante o déficit hídrico imposto. Essa informação pode ser reforçada pelo fato de ter ocorrido completo restabelecimento do status hídrico após a reidratação.

Diminuição significativa no TRA após 17 dias da suspensão da irrigação foi verificada em plantas de seringueira (Hevea brasiliensis), e o menor valor (70\%) foi observado no $35^{\circ}$ dia sem irrigação (CHEN et al. 2010). Da mesma forma, decréscimo no TRA em função da redução na disponibilidade de água no solo foi verificada por LOPES et al. (2005), em mudas de Eucalyptus crescendo sob diferentes lâminas de irrigação.

A lenta recuperação observada no TRA pode ter sido reflexo de efeitos do déficit hídrico nos vasos do xilema, pois, de acordo com CHEN et al. (2010), déficit hídrico severo pode trazer vários efeitos nos vasos do xilema, causando diminuição na condutividade hidráulica e consequente cavitação (OTIENO et al. 2005).

Em relação ao comportamento estomático das plantas, verificou-se que com o aumento no período de suspensão da irrigação, as plantas apresentaram declínio na condutância estomática (Figura 2), em virtude de redução na abertura estomática $\mathrm{e}$, consequentemente, queda na capacidade dos estômatos permitirem as trocas gasosas entre a planta e o meio externo.
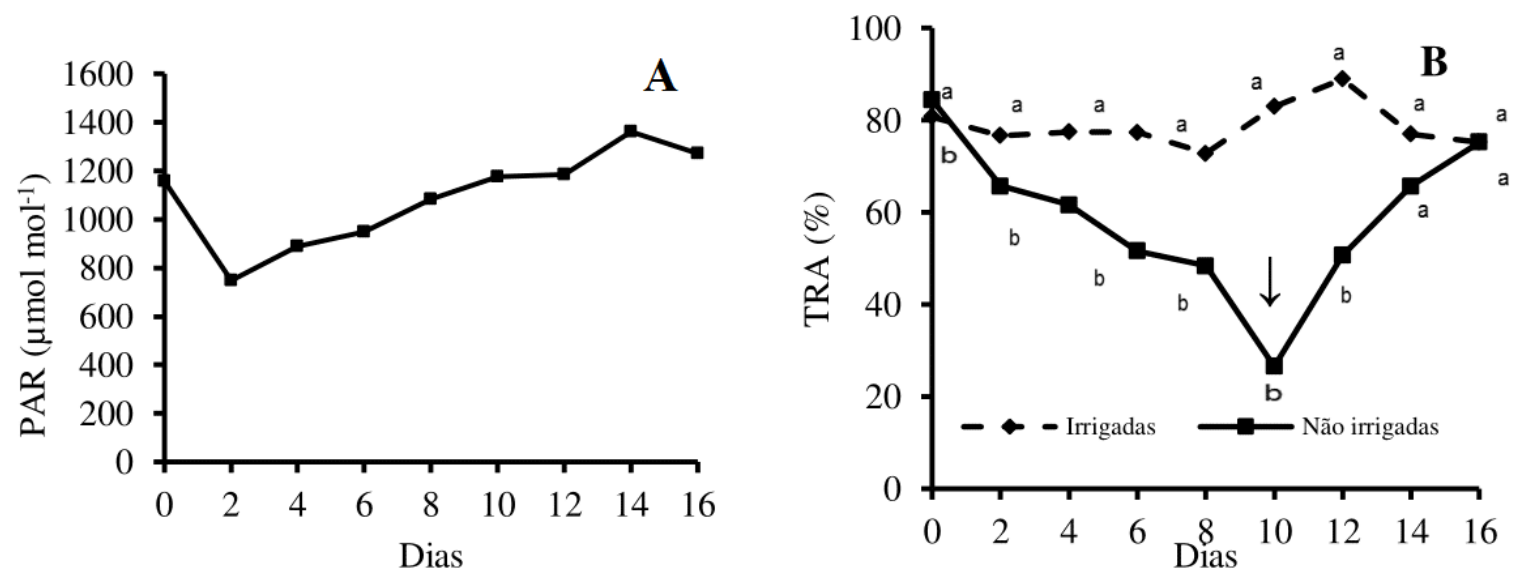

Figura 1. Radiação fotossinteticamente ativa (PAR) (A) e teor relativo de água (TRA) foliar (B) em plantas de ipê-roxo em função do déficit hídrico e posterior reidratação.

Médias seguidas de letras iguais não diferem estatisticamente entre si pelo teste de Tukey $(\mathrm{p} \leq 0,05)$. A seta indica o dia da retomada da irrigação.

Figure 1. Photosynthetically active radiation (PAR) and leaf relative water content (TRA) in Handroanthus impetiginosus in relation to the water deficit and subsequent rehydration.

Means followed by the same letters do not differ statistically by Tukey test ( $p \leq 0.05)$. The arrow indicates the day of resumption of irrigation. 
Nota-se que até o segundo dia após a suspensão da irrigação não houve diferença estatística entre os tratamentos. A partir do quarto dia, as diferenças entre os tratamentos se tornaram mais expressivas, e a condutância estomática das plantas não irrigadas (Figura 2A) reduziu em 44\% em relação às plantas irrigadas, com elevação progressiva nas diferenças à proporção que o período sem irrigação aumentou. No último dia da imposição do déficit hídrico, a condutância estomática das plantas irrigadas era $0,05 \mathrm{~mol} \mathrm{~m}^{-2} \mathrm{~s}^{-1}$, correspondendo a uma redução de $95 \%$ em relação às plantas irrigadas, cujo valor era $0,0025 \mathrm{~mol} \mathrm{~m}^{-2} \mathrm{~s}^{-1}$ (Figura 2). Diminuição na condutância estomática das plantas causada pelo déficit hídrico tem sido mostrada em inúmeros estudos (OLIVEIRA et al. 2005, OTIENO et al. 2005, CHEN et al. 2010). Apesar da existência da interação de vários fatores que controlam a condutância estomática, como a luz e a temperatura, o efeito do déficit hídrico fica evidente, revelando que o mesmo pode ser utilizado como indicador da deficiência hídrica (OLIVEIRA et al. 2005).

Após a retomada do fornecimento de água, verificou-se recuperação da condutância estomática, mesmo que de forma lenta (Figura 2). A igualdade estatística entre os tratamentos, observada no último dia de análise, evidencia o fato que o período de déficit imposto (10 dias) não causou danos irreversíveis no mecanismo estomático das plantas, possibilitando sua recuperação após a reidratação do substrato. No entanto, essa recuperação lenta, nos primeiros dois dias, podem ser devido, de acordo com OLIVEIRA et al. (2011), ao acúmulo de ácido abscísico (ABA) durante o período de déficit hídrico.

Em decorrência da diminuição na condutância estomática das plantas sob déficit hídrico, ocorreu redução na taxa de transpiração à proporção que o período sem receber água aumentava (Figura 2B). No segundo dia da suspensão da irrigação, o comportamento da taxa de transpiração nos dois tratamentos foi significativamente igual, mostrando que as plantas submetidas à deficiência hídrica ainda não apresentavam sinais de déficit hídrico, apesar do TRA das mesmas ser inferior ao das plantas irrigadas (Figura 1B). Possivelmente o teor de umidade do solo era suficiente para que as plantas mantivessem inalteradas suas atividades fisiológicas. Apenas a partir do quarto dia sem irrigação é que diferenças significativas entre os tratamentos foram notadas. As plantas irrigadas apresentaram valor máximo de taxa de transpiração no oitavo dia, reduzindo nos dias seguintes. Porém, esses valores continuaram superiores aos das plantas sob déficit hídrico, até o décimo quarto dia.

No décimo dia da suspensão da irrigação foi verificado o menor valor de taxa de transpiração nas plantas submetidas ao déficit $\left(0,302 \mathrm{mmol} \mathrm{m}^{-2} \mathrm{~s}^{-1}\right)$, correspondendo a uma redução de $77 \%$ em relação às plantas irrigadas, cuja taxa de transpiração era de $1,342 \mathrm{mmol} \mathrm{m}^{-2} \mathrm{~s}^{-1}$. NOGUEIRA et al. (1998), estudando os efeitos da suspensão da irrigação em plantas de canafístula-brava (Senna martiana), turco (Parkinsonia aculeata) e fedegoso (Senna occidentalis), espécies lenhosas presentes na Caatinga, observaram redução na transpiração após 20 dias de suspensão de irrigação. $\mathrm{O}$ mesmo comportamento foi verificado por GOMES et al. (2004) em plantas de laranjeira (Citrus sinensis) submetidas a déficit hídrico.

Após o restabelecimento do fornecimento de água às plantas não irrigadas, a taxa de transpiração dessas plantas aumentou progressivamente, mas diferença significativa entre essas e as plantas irrigadas foi observada apenas no sexto dia após, comportamento idêntico ao verificado na condutância estomática (Figura 2).

Em relação à taxa de fotossíntese, observouse que nas plantas não irrigadas ocorreu redução à medida que o déficit hídrico progrediu, apresentando diferença significativa no quarto dia após a suspensão da irrigação, em relação às plantas irrigadas (Figura 2). Semelhante ao observado na condutância estomática e na transpiração, noúltimo dia da suspensão da irrigação (10 dias), as plantas não irrigadas apresentaram taxa de fotossíntese muito baixa $\left(0,56 \mu \mathrm{mol} \mathrm{m}^{-2} \mathrm{~s}^{-1}\right)$, sendo esse valor equivalente a $81 \%$ ao verificado nas plantas irrigadas $\left(3,02 \mu \mathrm{mol} \mathrm{m}^{-2} \mathrm{~s}^{-1}\right)$ (Figura 2).

Nas plantas irrigadas, a taxa de fotossíntese variou muito pouco até o último dia do experimento (Figura 2C). Esse comportamento foi diferente do observado na condutância estomática e na transpiração, que reduziram, evidenciando que as alterações nessas variáveis não exerceram efeito na fotossíntese dessas plantas, pelo menos a partir do décimo dia do início dos tratamentos. Dessa forma, parece haver uma baixa relação entre condutância estomática e taxa de fotossíntese, conforme observado por COSTA \& MARENCO (2007) em plantas de andiroba (Carapa guianensis). Esses autores afirmaram que tanto a fotossíntese como a condutância estomática são 
parâmetros da planta que respondem simultaneamente a um conjunto de fatores que interagem de forma coordenada, mas altamente complexa.

Nos quatro primeiros dias ocorreu alteração acentuada na condutância estomática (Figura 2A), taxa de transpiração (Figura 2B) e taxa de fotossíntese das plantas irrigadas (Figura 2C) possivelmente devido à redução na radiação fotossinteticamente ativa (PAR) (Figura 1A). Em geral, a abertura dos estômatos responde à luz (exceto os estômatos das plantas com metabolismo CAM), baixa concentração de $\mathrm{CO}_{2}$, altas temperaturas e baixo déficit de pressão de vapor (DPV) (LAWSON \& BLAT 2014), os quais podem exercer efeito integrado no movimeto estomático (TALBOTT et al. 2003, WANG et al. 2008).

Após a retomada da irrigação das plantas não irrigadas, observa-se que as diferenças entre os tratamentos permaneceram elevadas (Figura 2). Nessas plantas, aumento em taxa de fotossíntese após a reirrigação ocorreu apenas depois quarto dia. É interessante observar que, ao final do período de avaliação (décimo sexto dia), os valores de taxa de fotossíntese das plantas não irrigadas não se igualaram aos das irrigadas, mas atingiram os mesmos valores do dia em que foram submetidas à suspensão da irrigação.
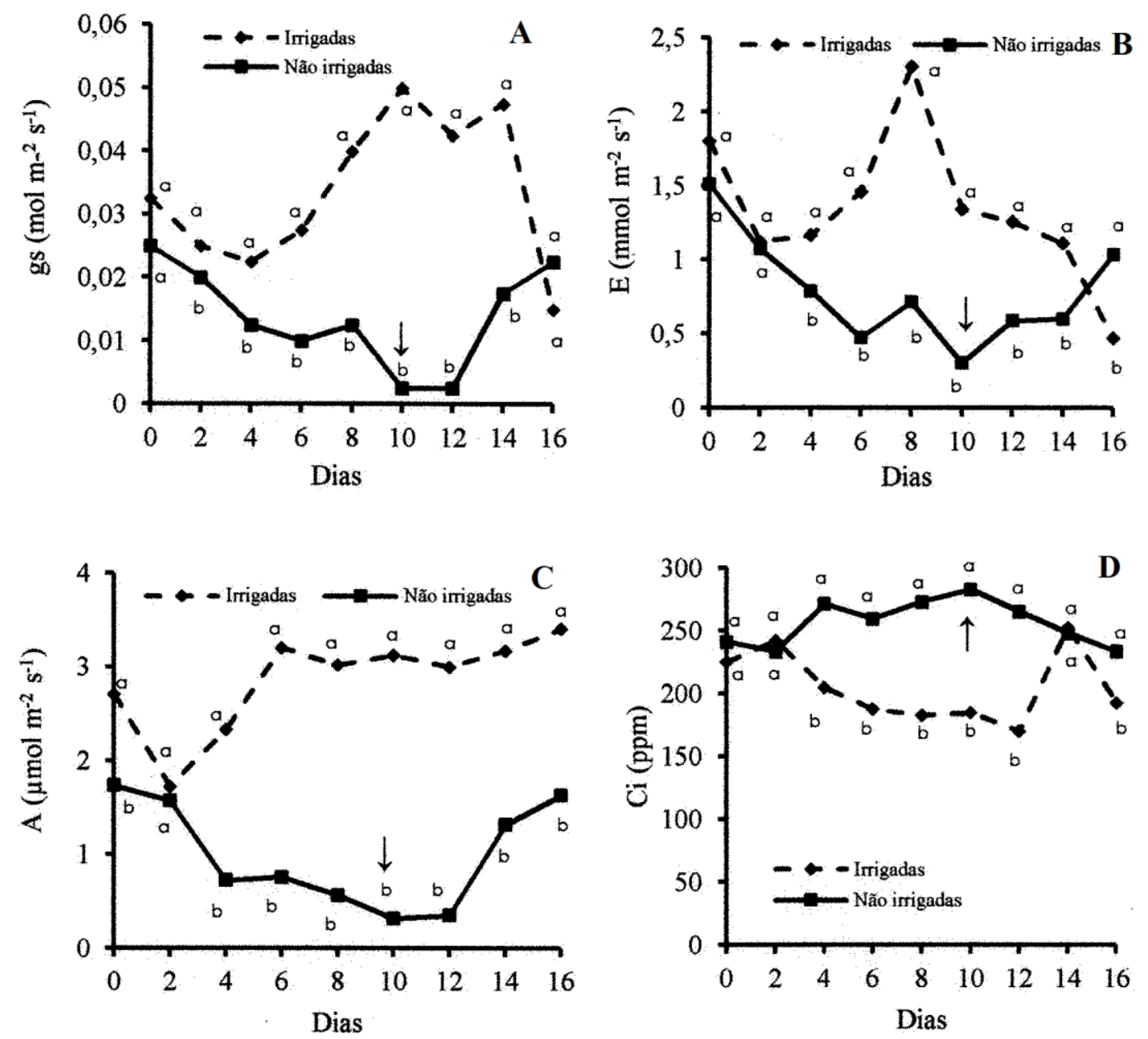

Figura 2. Condutância estomática (gs) (A), taxa de transpiração (E) (B), taxa de fotossíntese (A) (C) e concentração intercelular de $\mathrm{CO}_{2}(\mathrm{Ci})$ (D) em plantas de ipê-roxo em função do déficit hídrico e posterior reidratação.

Médias seguidas de letras iguais não diferem estatisticamente entre si pelo teste de Tukey $(\mathrm{p} \leq 0,05)$. A seta indica o dia da retomada da irrigação.

Figure 2. Stomatal conductance (gs), transpiration rate (E), photosynthetic rate (A) and intercellular $\mathrm{CO}_{2}$ concentration (Ci) in Handroanthus impetiginosus in relation to the water deficit and subsequent rehydration.

Means followed by the same letters do not differ statistically by Tukey test ( $p \leq 0.05)$. The arrow indicates the day of resumption of irrigation. 
A concentração intercelular do $\mathrm{CO}_{2} \quad(\mathrm{Ci})$ das plantas não irrigadas foi superior à das plantas irrigadas, após o segundo dia sem irrigação (Figura 2D), e esse comportamento permaneceu inalterado durante todo o período de suspensão da irrigação. Esse comportamento pode ser devido à redução na fotossíntese das mesmas (Figura 2C), resultando na redução da carboxilação e consequente acúmulo de $\mathrm{CO}_{2}$. Em plantas de cafeeiro (Coffea arabica), SOUZA (2012) observou aumento nos valores de Ci à medida que o período de déficit hídrico progredia, ao passo que os valores de gs, E e A reduziam.

Em decorrência do acúmulo de $\mathrm{CO}_{2}$ intercelular nas plantas não irrigadas, ocorreu redução também na eficiência de carboxilação (A/Ci) dessas plantas (Figura 3A). Isso significa redução na taxa de carboxilação à medida que a disponibilidade de água para as plantas diminuía. Dessa forma, a limitação à fotossíntese observada nas plantas não irrigadas não ocorreu apenas por fatores estomáticos, mas aspectos não estomáticos devem estar relacionados a esse fato. Reforçando essas informações, SOUZA (2012) observou redução na eficiência de carboxilação de plantas de cafeeiro com o decorrer do período de déficit hídrico, afirmando ainda que esse comportamento demonstra que a redução na fotossíntese dessas plantas ocorreu devido a limitação não estomática.

O déficit hídrico afeta a fotossíntese tanto por efeitos em aspectos estomáticos como não estomáticos. Embora seja bem estabelecido que o fechamento dos estômatos é um dos primeiros eventos desencadeados pelo déficit hídrico (CHAVES et al. 2002), existe uma grande controvérsia a respeito de qual é o fator dominante à medida que o déficit hídrico progride (LAWLOR \& CORNIC 2002, FLEXAS \& MEDRANO 2002).

Em relação ao fator estomático está o aumento na resistência às trocas gasosas, o que levaria à menor disponibilidade de $\mathrm{CO}_{2}$ intercelular, reduzindo a sua assimilação (SILVA et al. 2004b). Decréscimos significantes na concentração intercelular de $\mathrm{CO}_{2}$ (Ci) podem acarretar queda na fotossíntese devido à redução na concentração de $\mathrm{CO}_{2}$ necessário à atividade da ribulose-1,5-bisfosfato carboxilaseoxigenase (rubisco) (MACHADO et al. 2005). O efeito não estomático está relacionado às alterações causadas nos vários processos fotoquímicos, como redução no transporte de elétrons, afetando a formação de ATP e NADPH, e nos processos bioquímicos com a redução na eficiência carboxilativa e/ou na quantidade e atividade da rubisco e de outras enzimas do metabolismo fotossintético (TAIZ \& ZEIGER 2004).

Quanto à eficiência no uso da água (EUA) (Figura 3B), observa-se que houve diferença significativa entre os tratamentos apenas no último dia
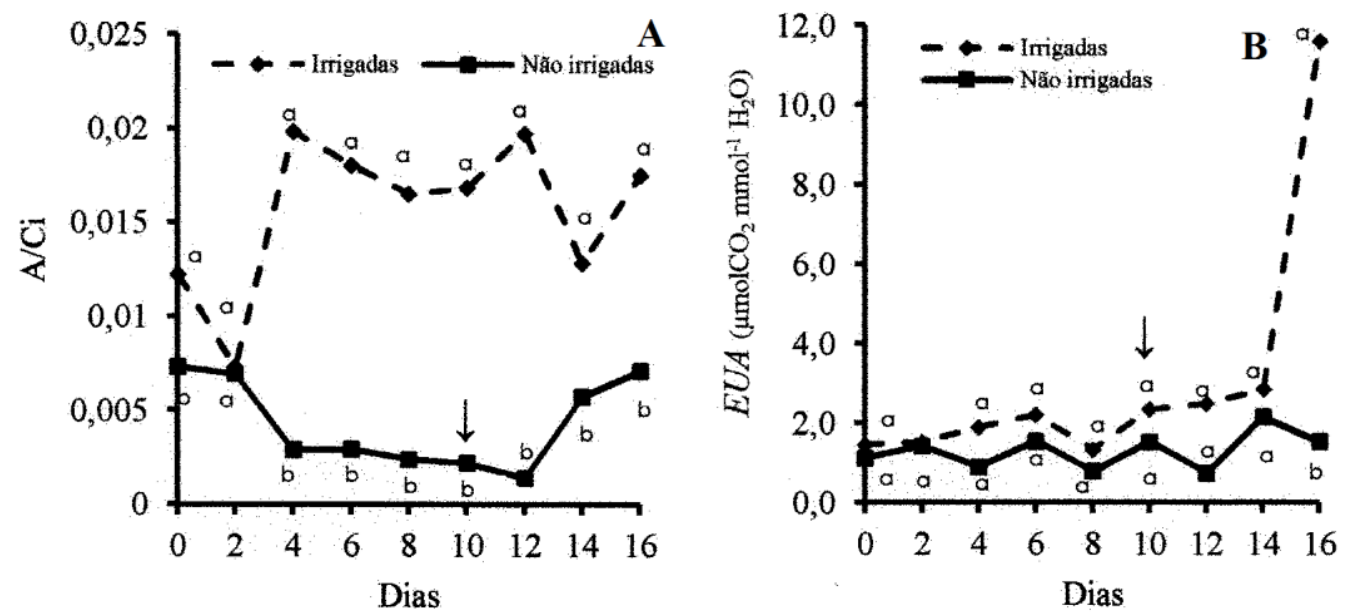

Figura 3. Eficiência de carboxilação (A/Ci) (A) e eficiência no uso da água (EUA) (B) de plantas de ipê-roxo sob déficit hídrico e posterior reidratação.

Médias seguidas de letras iguais não diferem estatisticamente entre si, pelo teste de Tukey $(p \leq 0,05)$. A seta indica o dia da retomada da irrigação.

Figure 3. Carboxylation efficiency (A/Ci) and water use efficiency (EUA) in Handroanthus impetiginosus in relation to the water deficit and subsequent rehydration.

Means followed by the same letters do not differ statistically by Tukey test ( $p \leq 0.05)$. The arrow indicates the day of resumption of irrigation. 
de avaliação. Além disso, ocorreu pouca variação nos valores, nas plantas não irrigadas, ao longo do período. $O$ fato de não ter ocorrido diferença estatística entre os tratamentos, durante o período de suspensão da irrigação indica que essas plantas conseguiram regular a perda de água por transpiração, porém sem afetar demasiadamente a fotossíntese. Concordando com esses resultados, em plantas de Eucalyptus grandis e E. citriodora, SILVA et al. (2004b) verificaram que a eficiência no uso da água, ou coeficiente transpiratório, não variou entre os diferentes níveis de água no solo.

\section{CONCLUSÃO}

$\mathrm{O}$ déficit hídrico reduziu de maneira rápida e progressiva o conteúdo relativo de água, a condutância estomática, a transpiração, a eficiência de carboxilação e a fotossíntese das plantas.

O déficit hídrico promoveu aumento na concentração intercelular de $\mathrm{CO}_{2}$.

Após a retomada do fornecimento de água, as plantas apresentaram recuperação nesses processos fisiológicos.

O déficit hídrico não afetou a eficiência no uso da água das plantas de ipê-roxo.

\section{REFERÊNCIAS}

BEZERRA FML et al. 2003. Feijão caupi e déficit hídrico em suas fases fenológicas. Revista Ciência Agronômica 34: 5-10.

CABRAL EL et al. 2004. Crescimento de plantas jovens de Tabebuia aurea (Manso) Benth. \& Hook. f. ex S. Moore submetidas a déficit hídrico. Acta Botanica Brasilica 18: 241-251.

CHAVES MM et al. 2002. How plants cope with water stress in the field. Photosynthesis and growth. Annals of Botany 89: 907-916.

CHEN JW et al. 2010. Gas exchange and hydraulics in seeedlings of Hevea brasiliensis during water stress and recovery. Tree Physiology 30: 876-885.

COSTA GF \& MARENCO RA. 2007. Fotossíntese, condutância estomática e potencial hídrico foliar em árvores jovens de andiroba (Carapa guianensis). Acta Amazonica 37: 229-234.

FIGUEIRÔA JM et al. 2004. Crescimento de plantas jovens de Myracrodruon urundeuva Allemão (Anacardiaceae) sob diferentes regimes hídricos. Acta Botanica Brasilica 18: 573-580.

FLEXAS J \& MEDRANO H. 2002. Drought-inhibition of photosynthesis in $\mathrm{C} 3$ plants: stomatal and non-stomatal limitation revisited. Annals of Botany 89: 183-189.

GEBREKIRSTOS A et al. 2006. Adaptation of five co- occurring tree and shrub species to water stress and its implication in restoration of degraded lands. Forest Ecology and Management 229: 259-267.

GOMES MMA et al. 2004. Interactions between leaf water potential, stomatal conductance and abscisic acid content of orange trees submitted to drought stress. Brazilian Journal of Plant Physiology 16: 155-161.

LAWLOR DW \& CORNIC G. 2002. Photosynthetic carbon assimilation and associated metabolism in relation to water deficits in higher plants. Plant, Cell and Environment 22: 275-294.

LAWSON T \& BLATT MR. 2014. Stomatal size, speed, and responsiveness impact on photosynthesis and water use efficiency. Plant Physiology 164: 1556-1570.

LOPES JLW et al. 2005. Efeitos da irrigação na sobrevivência, transpiração e no teor relativo de água na folha em mudas de Eucalyptus grandis em diferentes substratos. Scientia Forestalis 68: 97-106.

MACHADO EC et al. 2005. Respostas da fotossíntese de três espécies de citros a fatores ambientais. Pesquisa Agropecuária Brasileira 40: 1161-1170.

NOGUEIRA RJMC et al. 1998. Trocas gasosas e relações hídricas em plantas envasadas de três espécies da caatinga, submetidas à deficiência hídrica. Phyton 62: 37-46.

OLIVEIRA AKM et al. 2011. Gas exchange of potted Tabebuia aurea plants under hydric stress. Acta Scientiarum. Agronomy 33: 641-647.

OLIVEIRA AD et al. 2005. Condutância estomática como indicador de estresse hídrico em feijão. Engenharia Agrícola 25: 86-95.

OTIENO DO. 2005. Physiological and morphological responses to water stress in two Acacia species from contrasting habitats. Tree Physiology 25: 361-371.

PARDO JM. 2010. Biotechnology af water and salinity stress tolerance. Current Opinion in Biotechnology 21: 185-196.

PIMENTEL C. 2004. A relação da planta com a água. Seropédica: EDUR. 191p.

SILVA EC et al. 2004a. Aspectos ecofisiológicos de dez espécies em uma área de Caatinga no município de Cabaceiras, Paraíba, Brasil. Iheringia, Série Botânica 59: 201-205.

SILVA W et al. 2004b. Índice de consumo e eficiência do uso da água em eucalipto, submetido a diferentes teores de água em convivência com braquiária. Revista Floresta 34: 325-335.

SOUZA VF. 2012. Estudo de rede para compreender as respostas fotossintéticas de cafeeiros em condições de deficiência hídrica. Dissertação (Mestrado em Agronomia). Lavras: UFLA. 56p.

TAIZ L \& ZEIGER E. 2004. Fisiologia Vegetal. 3.ed. Porto Alegre: Artmed. 719p.

TALBOTT LD et al. 2003. Relative humidity is a key factor in the acclimation of the stomatal response to $\mathrm{CO}_{2}$. Journal of Experimental Botany 54: 2141-2147. 
WANG Y et al. 2008. Distinct light responses of the adaxial and abaxial stomata in intact leaves of Helianthus annuиs L. Plant, Cell and Environment 31: 1307-1316.

WHEATHERLEY PE. 1950. Studies in the water relations of the cotton plant. I. The field measurements of water deficits in leaves. New Phytologist 49: 81-97. 